\title{
IDENTITAS ARSITEKTUR MANDAR PADA BANGUNAN TRADISIONAL DI KABUPATEN MAJENE
}

\author{
Nurmiati Zamad', Alfiah² \\ Teknik Sipil Universitas Sulawesi Barat, Arsitektur UIN Alauddin Makassar \\ e-mail: *1nurmiatizamad@roketmail.com, 2alfiah@uin-alauddin.ac.id
}

\begin{abstract}
Abstrak_Penelitian bertujuan untuk mengetahui (1). Identitas Arsitektur Mandar Pada Bangunan di Kelurahan Banggae Kabupaten Majene berdasarkan nilai arsitekturalnya, agar bangunan dipahami secara visual (identity), kesesuaian bangunan ditinjau dari bentuk, pola ruang (compatibility) serta kejelasan struktur fisik sebagai orientasi (view) dan diterapkan melalui pemakaian ragam hias tradisional pada bagian-bagian tertentu yang bersifat ornamentasi, agar sesuai dengan penempatannya berdasarkan perkembangan bangunan tahun 1960-2015. (2) Mengidentifikasi faktor yang menyebabkan identitas Arsitektur Mandar masih digunakan pada bangunan. Lokasi penelitian di Kelurahan Banggae Kabupaten Majene. Metode digunakan dalam penelitian adalah survey lapangan dengan mengidentifikasi 25 sampel bangunan tradisional dari 403 populasi di Kecamatan Banggae Kabupaten Majene. Pengambilan sampel dilakukan secara acak dari satu kelurahan yang mewakili lokasi penelitian. Data dianalisis dengan menggunakan identifikasi dan perbandingan sesuai fakta dilapangan. Hasil penelitian menunjukkan bahwa ornamen bentuk atap khas Mandar dari segi fisik berupa penggunaan teppang atap (butungbutung) sebagian besar masih digunakan dengan nilai ( $\pm 52 \%)$. Ornamen yang bermakna simbolik ini sangat signifikan mengapa identitas arsitektur Mandar masih digunakan pada bangunan etnis Mandar tahun 1960-2010, terutama pada bangunan arsitektur Mandar kontemporer, dan dari segi non fisik dipengaruhi oleh faktor status sosial dan faktor lingkungan. Out-Put dari penelitian diharapkan dapat menjadi strategi pemanfaatan Identitas Arsitektur Mandar pada bangunan modern vernacular.
\end{abstract}

Kata kunci : Identitas, Tradisional, Arsitektur Kontemporer, Ornamen, Simbol

Abstract_ The study aims to determine (1). Identity of Mandar Architecture In Building in Kelurahan Banggae Majene Regency based on its architectural value, so that building is understood visually (identity), suitability of building in terms of shape, pattern of compatibility and clarity of physical structure as orientation (view) and applied through traditional decorative usage In certain parts of an ornamentation, to fit the placement based on the development of the building in 1960-2015. (2) Identify the factors that caused the identity of Mandar Architecture still used in buildings. Research location in Kelurahan Banggae Majene Regency. The method used in the research is a field survey by identifying 25 samples of traditional buildings from 403 populations in Banggae District Majene District. Sampling was done randomly from one kelurahan representing the research location. Data were analyzed using identification and comparison according to the facts in the field. The result of the research shows that the ornament of roof shape typical of Mandar from the physical aspect in the form of the use of teppang roof (butungbutung) is still mostly used with the value ( $\pm 52 \%)$. This symbolic meaningful ornament is so significant why Mandar architectural identity is still used in the Mandar ethnic buildings of 1960-2010, especially in contemporary Mandar architectural buildings, and in non-physical terms influenced by social status factors and environmental factors. OutPut from the research is expected to be a strategy of utilizing Mandar Architectural Identity in modern vernacular buildings.

Keywords : Identity, traditional, contemporary architecture, ornament, symbolc.

\footnotetext{
${ }^{1}$ Dosen Jurusan Teknik Sipil Universitas Sulawesi Barat

${ }^{2}$ Dosen Jurusan Teknik Arsitektur UIN Alauddin Makassar
} 


\section{PENDAHULUAN}

Kelompok etnis yang paling besar di Sulawesi Selalatan adalah Bugis dan Makassar. Suku Makassar, Bugis dan Mandar terkenal sebagai pusat kelahiran pelaut berjiwa patriotik, baik dimasa perang maupun dimasa damai. Pada abad XVI etnis Bugis-Makassar dan Mandar yang menghuni kawasan pantai mempunyai pelaut-pelaut ulung. Dengan perahu layar tradisionalnya mereka mengarungi lautan kepulauan Indonesia. Mereka berlayar untuk berniaga ke berbagai bandar niaga di Pulau Jawa, Sumatera, Malaka kepulauan Maluku di Kawasan Timur Indonesia, bahkan sampai ke Madagaskar (Mattulada1998:3). Dalam sistem sosial masyarakat Mandar ada strata sosial masyarakat yang menentukan arsitektur rumah tinggal mereka.

Latar belakang geografis, prasejarah dan sejarah Sulawesi Barat telah melahirkan kekayaan budaya yang menarik. Hal ini sering kali diikuti dengan munculnya berbagai persoalan lingkungan, akibat dari pendekatan pembangunan yang tidak berakar kepada konteks lokal. Terlepas dari pada itu, persoalan identitas lokal masih tetap menjadi pertanyaan tersendiri. Berdasarkan kesenjangan yang ada antara kondisi nyata dan teori yang ada tersebut, penulis menganggap perlu melakukan penelitian tentang dengan Identitas Arsitektur Mandar pada bangunan etnis Mandar di Kelurahan Banggae Kabupaten Majene, dimana pada periode tahun 1960-2010 dapat diketahui adanya perubahan pada bangunan arsitektur Mandar. Penulis membatasi waktu identifikasi yaitu sebelum tahun 1960, karena pada masa itu adalah masa kejayaan bangunan arsitektur Mandar, aturan-aturan serta kaidah-kaidah pembuatan bangunan masih dipertahankan dari pengaruh budaya luar, namun setelah tahun 1960 keatas sampai tahun 2010.

Berdasarkan uraian pada latar belakang tersebut, maka dapat di rumuskan masalah dalam bentuk pertanyaan sebagai berikut: pertama Bagaimana identitas arsitektur Mandar sejak zaman dulu tahun 1960 dan zaman sekarang ditahun 2010? Kedua, Faktor apa yang menyebabkan Identitas arsitektur Mandar masih digunakan pada bangunan. Tujuan penelitian ini adalah untuk mengidentifikasi identitas arsitektur Mandar pada bangunan di Kelurahan Banggae Kabupaten Majene berdasarkan nilai arsitekturalnya, agar bangunan bisa dipahami secara visual (identity), kesesuaian bangunan ditinjau dari bentuk,pola ruang (compatibility) serta kejelasan struktur fisik sebagai orientasi (view) dan diterapkan melalui pemakaian ragam hias tradisional pada bagianbagian tertentu yang bersifat ornamentasi,agar sesuai dengan penempatannya berdasarkan perkembangan bangunan tahun 1960-2016 dan mengidentifikasi faktor yang menyebabkan identitas arsitektur Mandar masih digunakan pada bangunan. Dari penelitian yang dilakukan ini diharapkan dapat memberikan manfaat, yaitu penelitian ini diharapkan agar masyarakat serta pemerintah daerah dapat bekerja sama dalam memelihara bangunan sebagai komunitas tempat hunian dan menciptakan kesesuai karakter serta ciri khas bangunan sesuai pada tempatnya dan masukan pada Peneliti selanjutnya yang berkaitan dengan Identitas Arsitektur Mandar pada bangunan di Kelurahan Banggae Kabupaten Majene. Lingkup penelitian yang meliputi: wilayah penelitian dalam Identitas Arsitektur Mandar pada bangunan di Kelurahan Banggae Kabupaten Majene, yaitu pada kawasan pemukiman dan perdangan kota Majene.

Identitas menjadi kata kunci Lynch memaknai identitas sebagai pencerminan adanya unsur individualitas yang berbeda dengan objek lain,sebagai identitas tersendiri (Lynch,1960). Sedangkan menurut Saliya Identitas adalah hasil kesadaran berpikir tentang pemisahan manusia dengan alam luar. Memiliki identitas adalah kebutuhan normal manusia, dan kadangkala meningkat menjadi suatu keharusan (Saliya,1986). Keinginan memiliki identitas haruslah dicermati dan dirunut dari elemen-elemen yang terkait dengan pembentukan identitas itu sendiri. Bahasa, ras, agama, sejarah, batas budaya tradisi selalu memainkan peran yang kadarnya berbeda dalam pembentukan atau sintesis suatu identitas. 
Budaya yang terbentuk kadangkala merupakan akumulasi dari superimposisi sejarah yang mengkristal. Bahkan menurut Dethier kadang identitas murni suatu budaya di negara ketiga mudah sekali terdistorsi, terkomersialisasi, ter-stereotipe oleh sejarah kolonialisme modern. Semakin kokoh suatu identitas, semakin kuat pula ia memenjarakan ide-ide baru, ekspansi, interpretasi baru,ataupun kontradiksi (Koolhas, 1996). Menurut Framton, di negara-negara dunia ketiga yang belum lama terbebas dari belenggu kolonialisme, dilema ini terjadi karena keinginan untuk ikut ambil bagian dalam arus modernisasi kadangkala tanpa disadari ikut mengorbankan bagian budaya masa lalu mereka (Framton, 1983). Hal tersebut pernah diungkapkan oleh David mengenai euphoria masyarakat dunia ketiga: An Obsession with the newness is characteristic of people in emerging Third World societies (David, 1990).

1. Bentuk dan Fungsi Arsitektur Sebagai Respon Terhadap Lingkungan

Manusia selalu berdampingan dengan alam dan tidak dapat melepaskannya dari batasan dan hukum-hukumnya. Semula arsitektur lahir sekadar untuk menciptakan tempat tinggal sebagai wadah perlindungan terhadap gangguan lingkungan: alam dan binatang (Rapoport, 1969). Dengan demikian bentuk dan fungsi dalam arsitektur adalah respon manusia terhadap lingkungan (Crowe, 1995). Suatu cara yang lahir begitu saja dan kemudian membentuk satu pola yang dianut bersama dan menjadi satu tradisi yang dikenal sebagai arsitektur vernakular (Rudolvsky 1964). Menurut Sutedjo (1982) memperkenalkan pula istilah archetype, yaitu bangunan pada suatu daerah yang sama memiliki bentuk dan ciri-ciri yang sama pula. Menurut Sutrisno (1984) terdapat hubungan erat antara bentuk, fungsi,dan alam. Schultz (1988), membagi tugas bangunan menjadi dua kutub utama yakni lingkungan fisik dan simbol yang saling berkaitan. Pallasma juga mengemukakan bahwa penghuni atau pengamat dalam arsitektur terhadap keseluruhan bentuk fisiknya tidak semata melayani fungsi arsitektur berkenaan dengan kenyamanan dalam pengertian termal, cahaya dan kekakuan secara fisik tetapi juga kesan, pengalaman dan makna yang terpendam yang mengajak dan diajak berkelana ke dalam keseluruhan penampakannya dalam sebuah geometri rasa. Seluruh kultur dalam sebuah lingkungan dapat saja mempengaruhi dan membentuk cara bagaimana arsitektur dibangun dan dikembangkan (Agrest, 1976). Lincourt (1999) seorang arsitek berkebangsaan Perancis, yang berkaitan dengan karya arsitektur adalah fenomena arsitektur merupakan suatu keseluruhan simbiosis yang terdiri dari lima elemen dasar.

Dari berbagai kajian teori mengenai identitas penulis menyimpulkan bahwa Identitas adalah merupakan ciri khas bangunan berdasarkan nilai arsitektural yang menjadikan bangunan bisa dipahami secara visual meskipun telah mengalami perubahan bentuk, fungsi atau berupa simbol akibat pengaruh unsur-unsur dari luar dan dalam pada bangunan serta akibat perkembangan teknologi baik secara secara fisik maupun non fisik.

2. Perubahan Warisan Budaya

Lingkungan fisik dan non fisik sangat memegang peranan penting dalam proses pertumbuhan dan perkembangan manusianya Robert (1969), Setiap aspek kehidupan selalu berkaitan dengan lingkungannya, sehingga telah menjadi bagian yang tidak bisa dipisahkan dari struktur masyarakat. Philip (1974), perubahan tersebut terjadi karena manusia senantiasa dihadapkan pada pilihan-pilihan yang timbul karena hubungan budaya tadi. Rapoport (1983), Linpton, seorang antropolog kenamaan Amerika menyatakan bahwa didunia ini tidakada lagi masyarakat yang berhak menyatakan bahwa kebudayaannya masih asli.

Kebudayaan Mandar terdiri atas asal usul pitu ulunna salu dan pitu baqbana binanga dan yang artinya kekuasan ditanah Mandar terdiri atas tujuah wilayah kerajaan di daerah pegunungan dan tujuh wilayah kerajaan di daerah pesisir (Mattulada dalam Koentjaraningrat, 1999). Sulawesi 
Barat semula merupakan wilayah provinsi Sulawesi Selatan, namun kemudian pada tanggal 5 Oktober 2004 dibentuk menjadi provinsi berdasarkan UU No. 26 tahun 2004. Bardasarkan hasil penelitian etnologi, suku Mandar merupakan keturunan melayu muda (deutro Melayu) yang berasal dari India belakang. Orang Mandar mengucapkan bahasa Mandar dan telah memiliki kesusasteraan tertulis sejak berabad-abad lamanya dalam bentuk lontar. Huruf yang dipakai adalah aksara lontara, sebuah sistem huruf yang berasal dari sanskerta. Berdasarkan pola morfologinya, arsitektur tradisional Mandar dapat dilihat dari beberapa segi sebagai berikut:

1. Pola Penataan Spatial

Identitas arsitektur tradisional Mandar tergambar dalam bentuk rumah tradisional yang disebut boyang.dikenal adanya dua jenis boyang, yaitu : boyang adaq dan boyang beasa. Boyang adaq ditempati oleh keturunan bangsawan, sedangkan boyang beasa ditempati oleh orang biasa. Simbolik lain dapat dilihat pada struktur tangga. Tatanan dan aturan rumah adat, tiga susun dan tiga petak menunjukkan makna pada filosofi orang Mandar yang berbunyi: da'dua tassasara, tallu tammallaesang artinya kurang lebih Tuhan dan Nabi Muhammad dan manusia yang tidak terpisahkan antara satu dengan yang lainnya saling membutuhkan (Ibrahim:1999:87). Adapun dua yang tak terpisahkan itu adalah aspek hukum dan demokrasi, sedangkan tiga saling membutuhkan adalah aspek ekonomi, keadilan, dan persatuan. Bentuk rumah Mandar hampir sama dengan rumah-rumah Bugis dan Makassar. Perbedaannya terletak pada bagian teras (lego-legonya) yang kadang-kadang lebih besar dengan atap mirip emper miring ke depan. Rumah ini merupakan rumah panggung yang berdiri di atas tiang-tiang untuk menghindari banjir dan binatang buas. Semakin tinggi ukuran kolong rumah menunjukkan semakin tinggi pula tingkat status sosial pemiliknya. Sebab dari status sosial yang akan menempati rumah tersebut.

Pemilihan waktu mendirikan boyang juga sangat penting, karena terkait dengan kepercayaan masyarakat tradisionalnya. Waktu yang baik selalu dihubungkan dengan keberuntungan dan keselamatan. Hari-hari baik adalah senin, kamis, dan jumat. Bulan-bulan tertentu dianggap kurang baik, seperti Muharram, Syafar, Jumadil Awal, dan Dzulkaiddah. Orientasi rumah boyang yang paling baik adalah pada arah yang mengandung makna positif, yaitu arah timur tempat matahari terbit. Setelah agama Islam masuk di daerah Mandar, maka muncullah pandangan baru bahwa arah barat juga baik. Arah barat dianggap menghadap ke kiblat. Arsitektur rumah Mandar umumnya tidak bersekat-sekat. Bentuk denah yang umum adalah rumah yang tertutup, tanpa serambi yang terbuka. Tangga depan biasanya di pinggir (Sumintardja,1981). Rumah Mandar juga dapat digolongkan menurut fungsinya (Mattulada dalam Koentjaraningrat, 1999). Secara spatial vertikal dapat dikelompokkan dalam tiga bagian berikut: a) Tapangan, b) Ruang/ Alawe boyang, dan c) Naung boyang, kolong rumah terletak di bagian bawah antara lantai dengan tanah

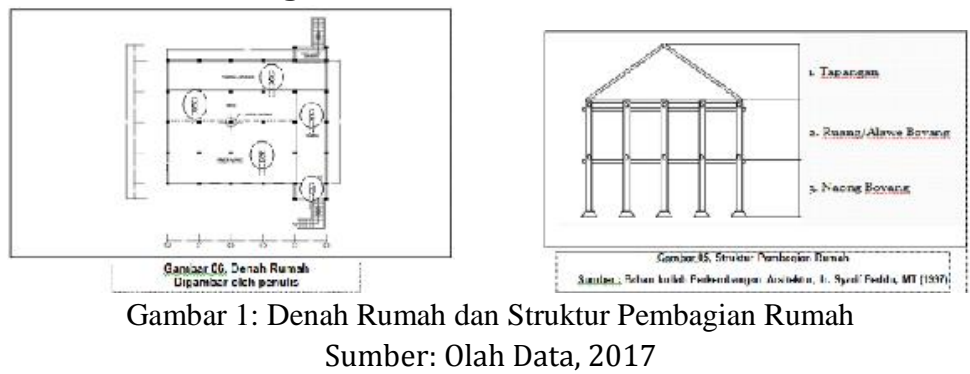

2. Pola Penataan Stilistika

a. Minimal memiliki empat petak atau 25 kolom (lima-lima) untuk Maraqdia dan tiga petak atau 16 kolom (untuk boyang biasa/sapo) 


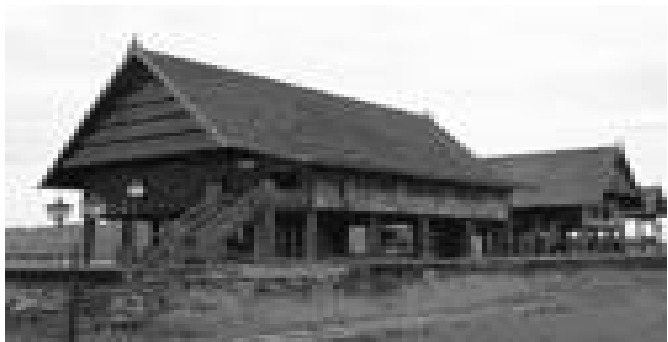

Gambar 2. Rumah Adat Mandar

Sumber: Internet www. Andi Amir Hamzah Sul (2009)

Sedangkan penataan spatial secara horisontal, pembagian ruang yang dalam istilah Mandar disebut lowang, dapat dikelompokkan dalam tiga bagian sebagai berikut: 1. tambing (ruang depan), 2. pequluwang atau ruang tengah, 3. songi,sifat sangat privat, 4. Legolego/Sondo-sondong: Ruang tambahan, 5. paceko: biasanya diletakkan di belakang atau samping. Secara terperinci ciri-ciri struktur rumah orang Mandar antara lain adalah:

1) Bentuk kolom adalah bulat untuk bangsawan, segiempat dan segidelapan untuk orang biasa

2) Terdapat pusat rumah yang disebut di possi (possi arriang) berupa tiang yang paling penting dalam sebuah rumah, biasanya terbuat dari kayu nangka atau durian, letaknya pada deretan kolom kedua dari depan, dan kedua dari samping kanan.

3) Tangga (endeq) diletakkan di depan atau belakang, dengan ciri-ciri: dipasang di olo boyang atau di lego-lego.

4) Arahnya ada yang sesuai dengan panjang rumah atau sesuai lebar rumah.

5) Atap (Ateq) berbentuk segitiga sama kaki yang digunakan untuk menutup bagian muka atau bagaian belakang rumah

\section{METODOLOGI}

Penelitian ini sifatnya eksploratif yang merupakan jenis studi kasus dengan survey dan pengamatan langsung di lapangan. Penelitian menggunakan pendekatan kualitatif dengan kecenderungan deskriptif dan mengekasplorasi kecenderungan aristektur yang terjadi.

1. Letak Wilayah

Secara geografis, batas-batas wilayah Kota Majene adalah sebagai berikut: Sebelah Utara dengan Kecamatan Pamboang, sebelah Selatan dengan Teluk Mandar, sebelah Timur dengan Kabupaten Polewali Mandar dan sebelah Barat dengan Kecamatan Pamboang dan Selat Makassar.

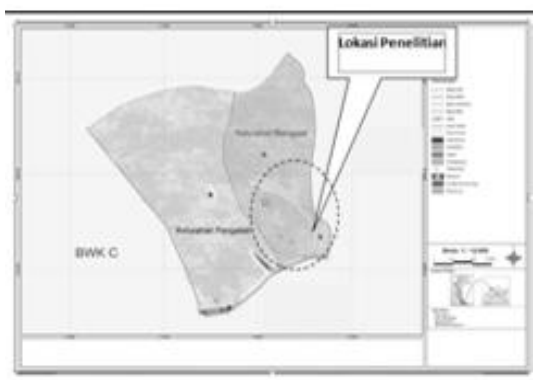

Gambar 3. Peta Pemukiman Banggae Sumber: BAPPEDA Kabupaten Majene 2008-2010 
2. Luas Wilayah

Kabupaten Majene adalah salah satu dari 5 Kabupaten/Kota dalam propinsi Sulawesi Barat dengan panjang pantai $125 \mathrm{Km}$ yang terletak di pesisir pantai Sulawesi Barat memanjang dari Selatan ke Utara dengan luas 947,84 Km. Ibukota Kabupaten Majene.

\section{HASIL DAN PEMBAHASAN}

\section{A. Deskripsi Kedudukan Kawasan Pemukiman Kelurahan Banggae Kecamatan Banggae Kabupaten Majene}

Kelurahan Banggae Kecamatan Banggae adalah kawasan perdagangan dan pemukiman. Beragam etnis tinggal di perkampungan ini, antara lain Mandar, Bugis, Sunda, Jawa dan suku lainnya, yang dominan adalah Mandar dan Bugis. Berdasarkan letak dan lokasi penelitian diKecamatan Banggae Kelurahan Banggae, luas wilayah 46,04 $\mathrm{Km}^{2}$ yang berjumlah penduduk 7.092 juta/jiwa. Penelitian difokuskan pada Kelurahan Banggae, Kabupaten Majene dengan jumlah sampel 25 bangunan.

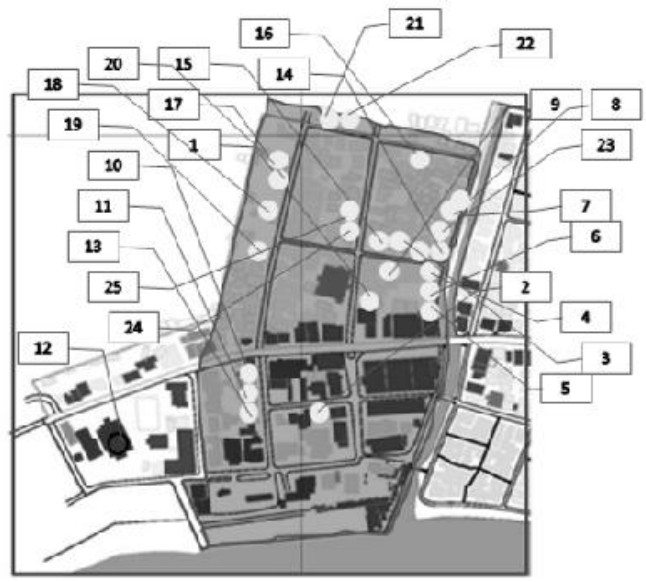

Gambar 4. Peta Ekisting Lokasi Penelitian di Kelurahan Banggae Sumber : BAPPEDA Kab. Majene 2008

Tabel 2. Usia bangunan dan fungsi bangunan sampel

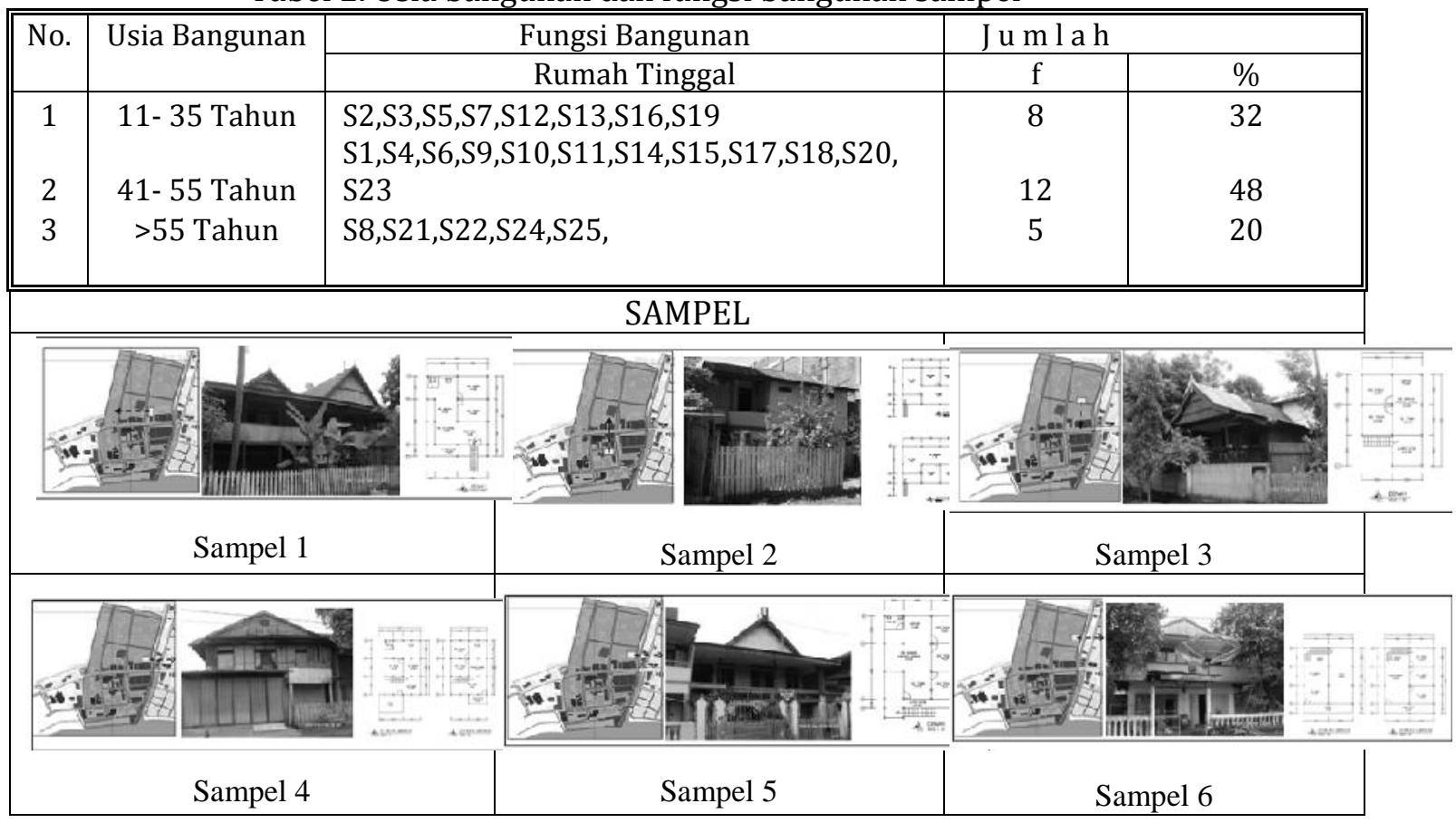




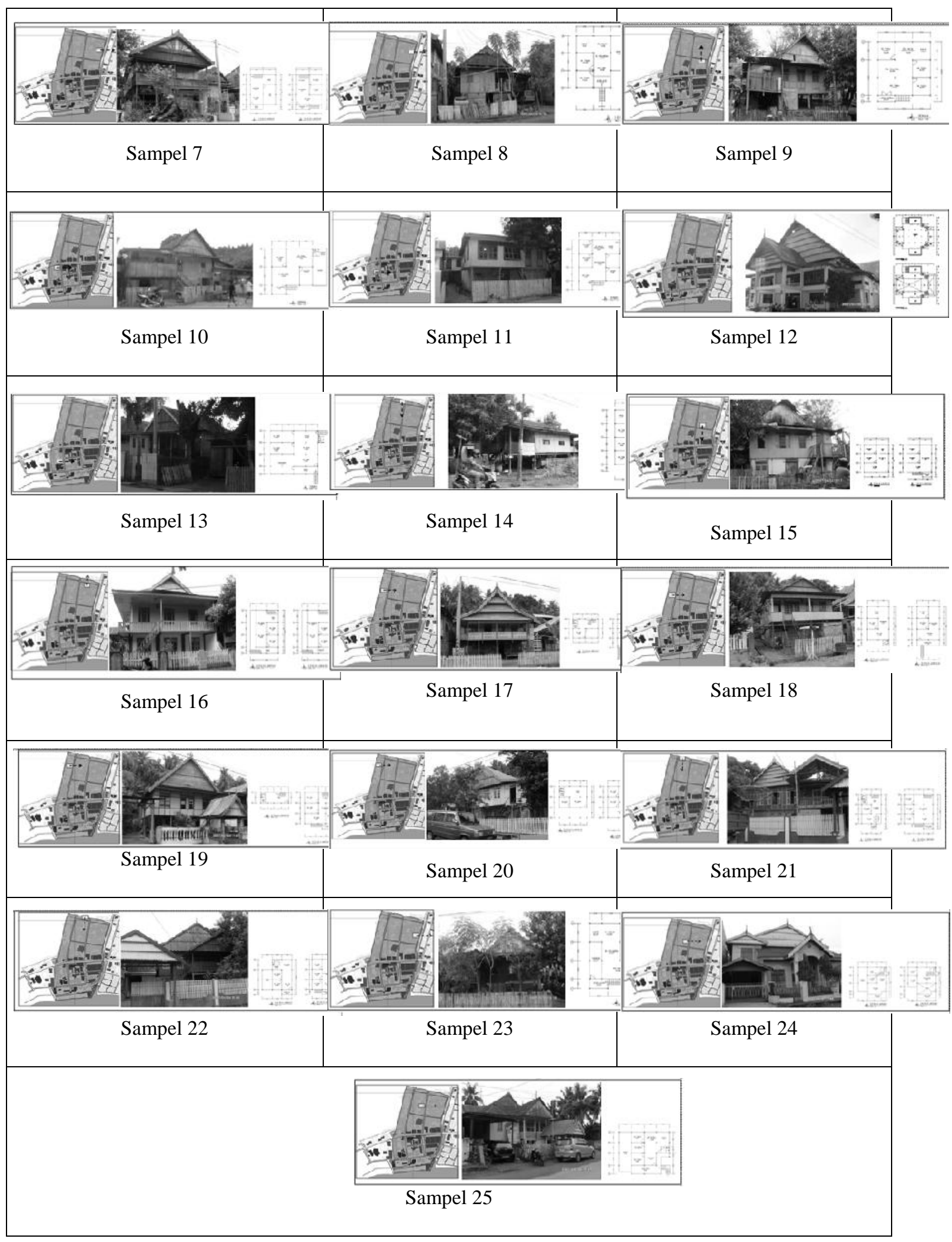




\section{B. Sejarah Perkembangan Arsitektur Mandar pada Bangunan di Kelurahan Banggae tahun 1960 sampai tahun 1990}

Perkembangan arsitektur Mandar sebelum tahun 1960 sampai tahun 1990 ketas, menurut hasil penelitian dilokasi kelurahan Banggae Kabupaten Majene dapat dilihat pada table identifikasi berikut:

Tabel 3. Identifikasi Perkembangan Arsitektur Mandar pada Bangunan di Kelurahan Banggae Kabupaten Majene

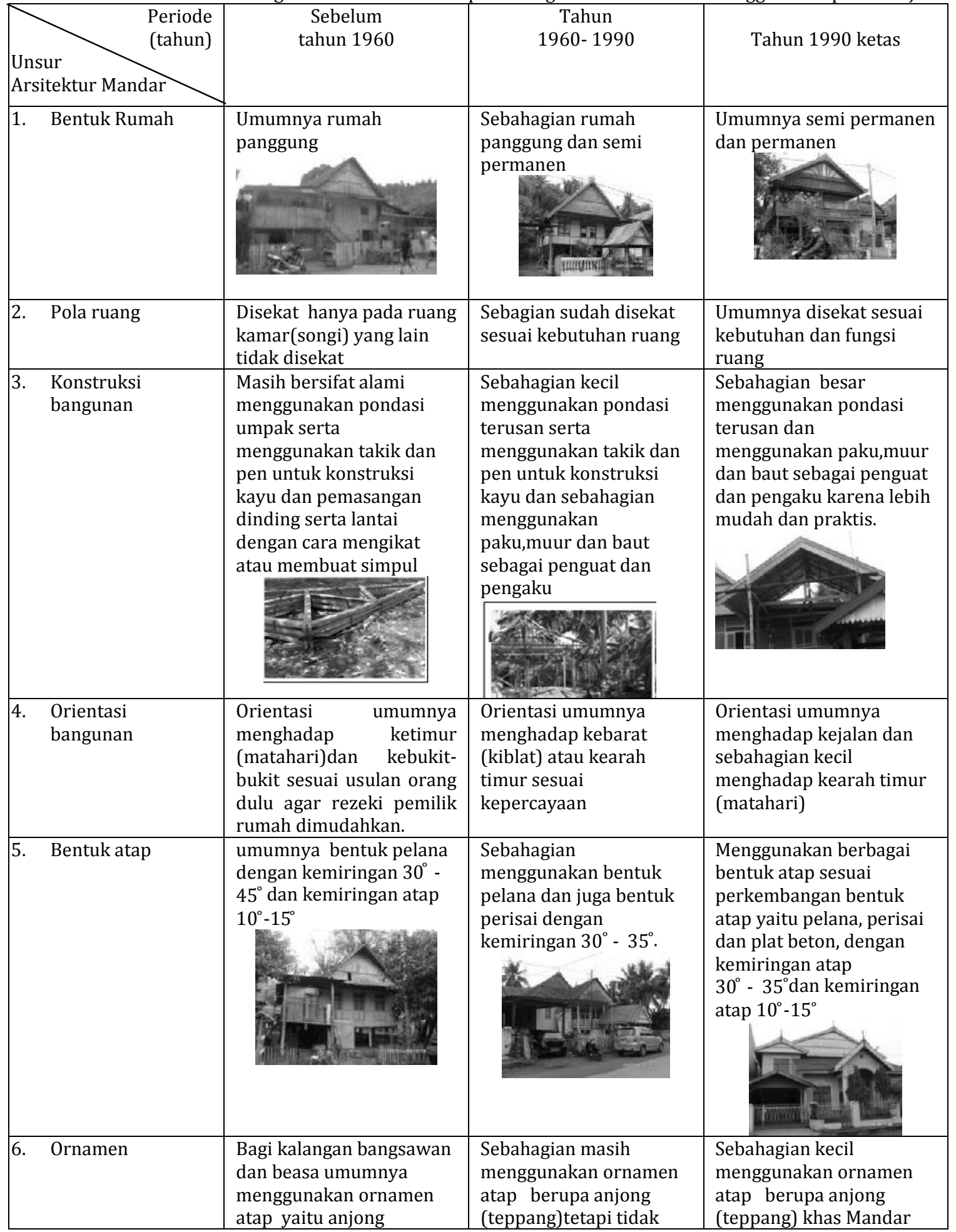




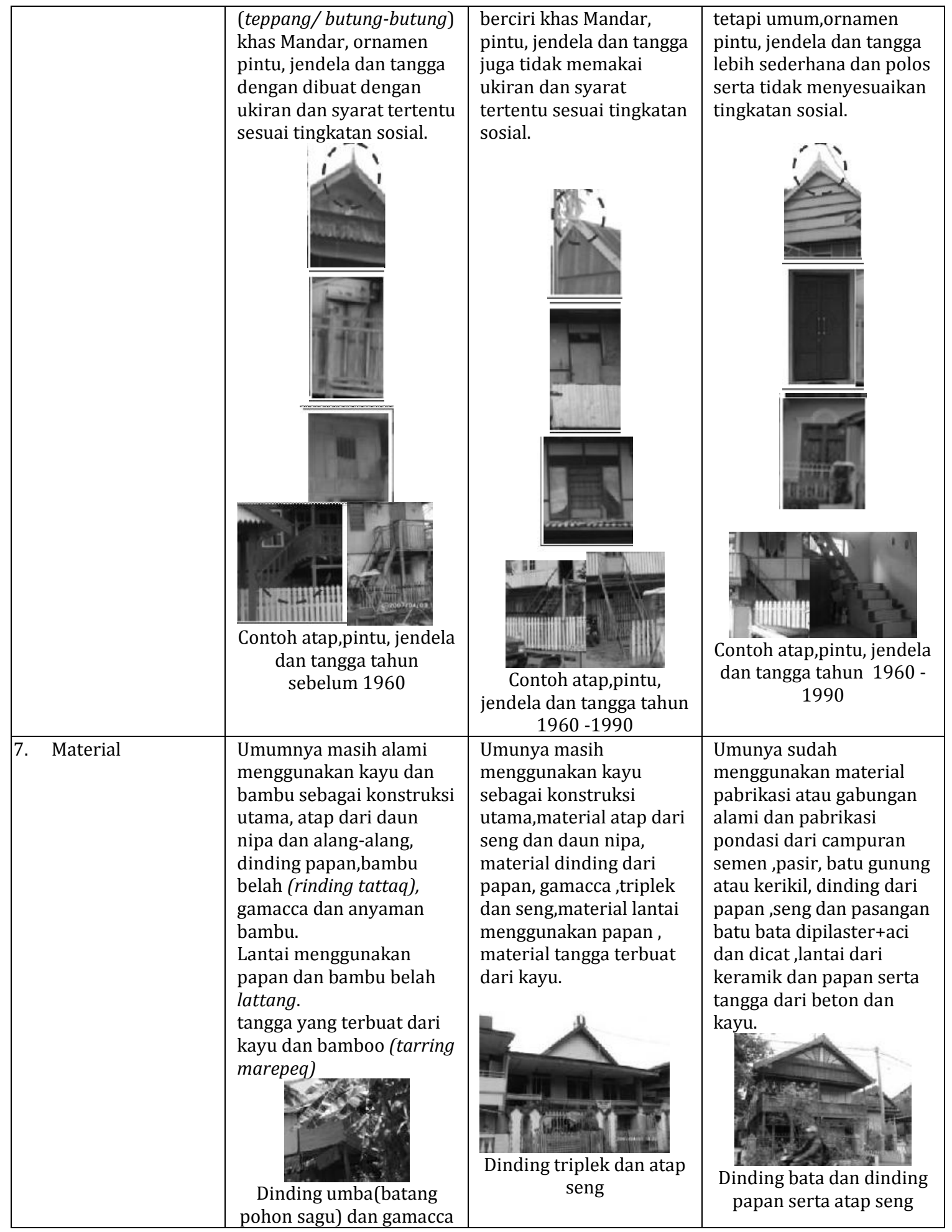

Sumber: Olah Data, 2017

\section{Faktor yang Mempengaruhi Perkembangan Arsitektur Mandar Pada Bangunan di Kelurahan Banggae}

Hasil analisis menunjukkan bahwa terdapat perubahan identitas arsitektur Mandar yang signifikan pada bangunan etnis Mandar, setelah tahun 1960 sampai tahun 2010 terutama pada bangunan arsitektur Mandar kontemporer yang disebabkan karena pengaruh antara lain: 1). Aspek sosial yaitu: status sosial (bentuk teppang atap, susunan tumbaqlayar dan simbolik tangga, 2) Aspek 
budaya yaitu: kondisi iklim (kemiringan atap dan penggunaan bahan bangunan) dan 3) Aspek ekonomi yaitu: mata pencaharian dan tingkat pendapatan.

\section{KESIMPULAN}

Hasil penelitian ini menunjukkan bahwa ornamen bentuk atap khas Mandar dari segi fisik berupa penggunaan teppang atap (butung-butung) sebagian besar masih digunakan dengan nilai $( \pm$ $52 \%$ ). Ornamen yang bermakna simbolik ini sangat signifikan mengapa identitas arsitektur Mandar masih digunakan pada bangunan etnis Mandar tahun 1960-2010, terutama pada bangunan arsitektur Mandar kontemporer, dan dari segi non fisik dipengaruhi oleh faktor status sosial dan faktor lingkungan.

Dari kajian Indentitas Arsitektur Mandar pada Bangunan di Kelurahan Banggae Kabupaten Majene adalah upaya untuk menggali nilai dari kearifan arsitektur tradisional lokal dan sebagai upaya transformasi, pewarisan nilai dan teknologi arsitektur tradisional dari para sesepuh, cerdik cendekia bidang budaya, sosiologi dan arsitek rumah tradisional yang diharapkan berjalan baik dan memiliki peluang pasar, dengan terwujudnya kelestarian arsitektur tradisional Mandar pada bangunan akan dapat merajut kembali kejayaan masa lalu yang bermanfaat dan menjadi kebanggaan masa kini. Warisan itu diwujudkan dalam explicit knowledge, yang sangat kita perlukan dalam memantapkan konsepsi ketahanan budaya lokal etnis oleh generasi masa kini dan generasi penerus dalam menghadapi tantangan masa mendatang.

\section{DAFTAR PUSTAKA}

Abbas Ibrahim, 1999, Pendekatan Budaya Mandar, Makassar

Artikel Arsyad Ardy, Rabu 7 Januari 2009, Kembali Kerumah Tradisional (Internet"http"//id. Wikipedia. Org/wiki Suku Mandar, Kategori Suku Bangsa Indonesia.

Faisal , 2007, Arsitetur Tradisional Mandar Provinsi Sulawesi Barat

Kila Syahrir, 2000, Sejarah dan Budaya Masyarakat Suku Bangsa Mandar, Direktorat Jenderal Kebudayaan Balai Kajian Sejarah dan Nilai Tradisional Makassar

Laporan Penelitian Sejarah dan Nilai Tradisional Sulawesi Selatan, Depdikbud Ujung Pandang, Direktorat Jenderal Kebudayaan, Balai Kajian Sejarah dan Nilai tradisional Ujung Pandang 1994/1995.

Mattulada, 1982, Geografi Budaya Daerah Sulawesi Selatan.Depdikbud Ujung Pandang. Muthalib Abdul, 1977, Kamus Bahasa Mandar, Pusat Pembinaan dan Pengembangan Bahasa Departemen Pendidikan dan Kebudayaan, Jakarta 